\title{
RECURRENCE IN KEYNESIAN MACROECONOMIC MODELS
}

\author{
VOLKER BÖHM ${ }^{1}$ \\ Lehrstuhl für Volkswirtschaftslehre, Wirtschaftstheorie \\ Universität Mannheim \\ Postfach $103462, D-W-6800$ Mannheim
}

\section{Introduction}

The development of new mathematical techniques in the theory of nonlinear dynamic systems has greatly enlarged the analytical basis for modern business cycle theory in economics. The elaborate theory of one-dimensional systems offers a large spectrum of methods and results indicating a great degree of different dynamic phenomenae which were not known before. Its impact on dynamic economics can already be found in a large number of recent publications. One of the most surprising class of results is given by the long list of contributions examining chaotic behavior in one-dimensional competitive systems (see for example the contributions in [10]).

In spite of the formal elegance and the portrayal of new and interesting results, competitive business cycle theory analyses intertemporal allocation problems within market clearing models, which, in general, cannot describe dynamic processes (see Grandmont [9]). The equilibrium requirement and the perfect foresight assumption together generate infinite sequences of equilibrium prices and allocations only, for which a forward recursive time map cannot be constructed in many cases.

Modern contributions to non-market clearing theories also applied the new techniques (see the recent survey by Lorenz [14]). One of the models studied frequently in that literature is the one originally proposed by Kaldor[13] in 1940. Dana/Malgrange [5] performe extensive simulations for a Kaldor type model. They show that varying a parameter of the model changes a stable fixed point to a closed orbit which, after a further increase of the parameter, becomes unstable itself. Thus, strange attractors or possibly chaos occur. In contrast to the competitive business cycle theory, however, these Keynesian models seldom are built on the same level of microeconomic basic principles. To some they are therefore considered too much ad hoc and unacceptable. Moreover, a comparison of the two types of models or their results is essentially futile since different methodologies are used for different economic models which leaves no room for a meaningful comparison.

\footnotetext{
${ }^{1}$ I am indebted to Markus Lohmann for his priceless assistance in computational matters at all stages of this research. Generous financial support by the University of Melbourne is gratefully acknowledged.
} 
The present paper represents an attempt to overcome some of these fundamental disparities. It uses features of Keynesian disequilibrium in an overlapping generations model. Thus, the same natural microeconomic basis as in competitive business cycle theory is used. In this way, some of the fundamental difficulties of the market clearing approach are avoided while the advantages of the demographic structure of overlapping generations models is maintained. Moreover, the market clearing situation becomes a special case of the disequilibrium. Thus, it is hoped that a meaningful comparison of the results of the two classes of models becomes possible.

Here the prototype model proposed in [4], is developed further. There the dynamic elements of the model were fully described, but no dynamic analysis was carried out. However, it was shown that for a two class consumer model the properties of the set of steady states imply that stable monotonic trajectories cannot be expected in many cases. Here the dynamic analysis will be presented for a one class consumer model. This model resembles most closely the standard Keynesian AD-AS model in its temporary form.

\section{The Model}

Consider an economy which evolves over time $t=1,2, \ldots$. In each period $t$ one homogeneous output is produced from homogeneous labor as the only input factor. Labor and output are not storable and output is produced instantaneously. Fiat money is the only store of value between periods. Its price is equal to one in all periods. Thus money serves as a unit of account and as a store of value. Let $p_{t}$ and $w_{t}$ denote the price of output and the wage rate in period $t$ respectively in terms of money.

The set of agents in the economy consists of a government, a firm, and of consumers. The government and the firm are both infinitely lived. The set of consumers has the overlapping generations structure.

\section{- Government}

The government purchases a quantity $g \geq 0$ of the commodity in each period at the market price $p_{t} \geq 0$, and it raises revenue by levying a proportional income tax on young consumers at the rate $\operatorname{tax}, 0 \leq \operatorname{tax} \leq 1$. Since economic activity determines the level of tax revenue, budget deficits and surpluses will typically occur. These are financed through money creation or destruction which constitutes the only source for changes in the money stock held by consumers. Thus their net asset position changes if and only if the deficit of the government is nonzero. There are no monetary transfers or lump sum taxes. 


\section{- Consumers}

Each generation of consumers consists of one consumer only, who lives and consumes for two consecutive periods. Each consumer supplies a fixed amount of labor $L_{m a x}>0$ during the first period of his life and receives wage income as well as profit. An old consumer neither receives any income nor any government transfers, so that all consumption during the second period of a consumer's life has to be financed through savings.

Let $M_{t} \geq 0$ denote the amount of money held by an old consumer at the beginning of period $t$. Then, given the current commodity price $p_{t}$, consumption demand of the old consumer is given by $M_{t} / p_{t}$.

Preferences of young consumers over consumption plans $\left(x_{t}, x_{t+1}\right) \geq 0$ are given by an intertemporal utility function $u: \mathbb{R}_{+}^{2} \rightarrow \mathbb{R}$, which satisfies the following assumption:

\section{Assumption C: (Preferences)}

1. $u: \mathbb{R}_{+}^{2} \rightarrow \mathbb{R}$

2. $u$ is $C^{2}$, strictly monotonic, strictly quasi-concave, homothetic

3. for any $\left(x_{t}^{n}, x_{t+1}^{n}\right) \gg 0$

$$
\begin{gathered}
\frac{\partial u}{\partial x_{t}}\left(x_{t}^{n}, x_{t+1}^{n}\right) \rightarrow+\infty \text { if } x_{t}^{n} \rightarrow 0 \\
\frac{\partial u}{\partial x_{t+1}}\left(x_{t}^{n}, x_{t+1}^{n}\right) \rightarrow+\infty \text { if } x_{t+1}^{n} \rightarrow 0
\end{gathered}
$$

Given the preferences of a young consumer, his consumption/savings decision will depend on his net income $Y^{\text {net }}$ in the first period of his life and on his price expectations for the second period. These will be taken to be point forecasts which the cosumer makes on the basis of past prices. Given his forecast $p_{t+1}^{e}$ for the price in period $t+1$, define $\theta_{t}^{e}=p_{t+1}^{e} / p_{t}$. Then, an optimal consumption and savings plan is given by the solution of

$$
\max \left\{u\left(x_{t}, x_{t+1}\right) \mid p_{t} x_{t}+p_{t+1}^{e} x_{t+1} \leq Y^{n e t}\right\}
$$

Because of Assumption C, the solution of the consumers optimization problem yields the notional commodity demand $x_{t}^{*}$ in the first period of his life as

$$
x_{t}^{*}=\arg \max \left\{u\left(x_{t}, \frac{Y^{n e t}-p_{t} x_{t}}{p_{t+1}^{e}}\right)\right\},
$$

which can be written as

$$
x_{t}^{*}=c\left(\frac{p_{t+1}^{e}}{p_{t}}\right) \frac{Y^{n e t}}{p_{t}}=c\left(\theta_{t}^{e}\right) \frac{Y^{n e t}}{p_{t}}
$$


His notional savings, i. e. his demand for money then is

$$
S_{t}^{*}=\left(1-c\left(\theta_{t}^{e}\right)\right) Y^{n e t} .
$$

The homotheticity of the utility function implies the particular form of the demand function. The function $c\left(\theta_{t}^{e}\right)$ is the average and marginal propensity to consume which depends on relative expected prices only, and lies strictly between zero and one. Thus consumption demand and the demand for money will always be positive as long as current, expected prices, and net income are positive.

For an analysis of the temporary structure of the model expected prices are essentially a parameter for the economy at time $t$. However, for a full dynamic analysis an explicit description has to be given of how young consumers make a particular forecast. Here it is assumed that the expected prices by consumers depend on observed prices over some finite past and that all generations use the same expectations function with an identical length of memory.

Let $\tau=0,1,2,3, \ldots$ denote the number of periods before $t$ for which generation $t$ considers past prices to be relevant for their forecast. Then, the expected price $p_{t+1}^{e}$ for period $t+1$ will be a function of the vector of past and current prices $\left(p_{t}, p_{t-1}, p_{t-2}, \cdots, p_{t-\tau}\right)$ which will be of the following general form:

$$
p_{t+1}^{e}=p_{t} \Psi\left(\frac{p_{t}}{p_{t-1}}, \cdots, \frac{p_{t+1-\tau}}{p_{t-\tau}}\right)
$$

Written more compactly one obtains

$$
\theta_{t}^{e}=\Psi\left(\theta_{t-1}, \cdots, \theta_{t-\tau}\right),
$$

in other words, generations of consumers make a point forecast of the inflation rate from $t$ to $t+1$ on the basis of the past $\tau$ inflation rates. Apart from continuity and inflation/deflation confirmation no further specific assumption will be imposed on $\Psi$.

Assumption E: (Expectations)

1. $p_{t+1}^{e}=p_{t} \Psi\left(\frac{p_{t}}{p_{t-1}}, \cdots, \frac{p_{t+1-\tau}}{p_{t-\tau}}\right)$

2. $\Psi: \mathbb{R}_{++}^{\tau} \rightarrow \mathbb{R}_{++}$continuous 
3. $\Psi(\theta, \ldots, \theta)=\theta \quad \forall \theta>0$

4. $\Psi \equiv 1 \quad$ if $\tau=0$.

\section{- Producer}

In each period $t$ the production of output is instantaneous from labor. There is no inventory holding. The capital stock of the economy is constant and one firm produces all output while attempting to maximize current profits. Let $F: \mathbb{R}_{+} \rightarrow \mathbb{R}_{+}$denote the production function of the firm in each period, so that output $y_{t}=F\left(z_{t}\right)$ where $z_{t}$ denotes labor input. Then, given the current wage rate $w_{t}$ and the current commodity price $p_{t}$, the firm solves the problem

$$
\max \left\{p_{t} y_{t}-w_{t} z_{t} \mid y_{t} \leq F\left(z_{t}\right)\right\}
$$

The following standard assumptions will be made:

Assumption F: (Production)

1. $F: \mathbb{R}_{+} \rightarrow \mathbb{R}_{+} ; y=F(z)$

2. $F$ is $C^{2}$, strictly monotonic, strictly concave

3.

$$
F(0)=0 \quad \lim _{z \rightarrow \infty} F(z)=\infty
$$

$$
F^{\prime}(0)=\infty \quad F^{\prime}(\infty)=0
$$

Let $\alpha_{t}=w_{t} / p_{t}$ denote the real wage in period $t$. Then, one obtains as notional labor demand of the firm

$$
z_{t}^{*}=h\left(\alpha_{t}\right)=\arg \max \left\{F(z)-\alpha_{t} z\right\}
$$

and as notional commodity supply

$$
y_{t}^{*}=F\left(h\left(\alpha_{t}\right)\right)
$$

Clearly, under Assumption F labor demand and commodity supply are strictly positive at all positive real wages $\alpha_{t}$. 


\section{Temporary Feasible States}

For the simple macroeconomic model considered here, the market structure and the set of agents imply for any period $t$ the same type and number of feasible situations as in all well known macroeconomic models built as general equilibrium models with quantity rationing. Thus for any given pair of the wage rate and the commodity price, feasibility and the one-sidedness assumption of rationing imply that there may exist three distinct disequilibrium situations labeled Keynesian unemployment, classical unemployment, repressed inflation, or one of the four possible boundary cases. Since labor supply is fixed and exogenously given at all prices and wages, the determination of these states can be carried out in the same simple fashion as in the traditional AD-AS model. This means that the feasibility considerations can be decoupled from the spillover structure of demand and supply behavior of the agents.

\section{- Aggregate Demand}

Consider the situation on the commodity market first. Any level of feasible output $y_{t}$ has to be equal to the sum of the quantities demanded by the government, the young consumer, and by the old consumer, i. e.

$$
y_{t}=\frac{M_{t}}{p_{t}}+c\left(\theta_{t}^{e}\right)(1-\operatorname{tax}) y_{t}+g
$$

Let $m_{t}=M_{t} / p_{t}$ denote real balances. Solving for $y_{t}$ yields the aggregate demand function $D\left(m_{t}, \theta_{t}^{e}, g, \operatorname{tax}\right)$ given by

$$
y_{t}^{D}=D\left(m_{t}, \theta_{t}^{e}, g, \operatorname{tax}\right)=\frac{m_{t}+g}{1-c\left(\theta_{t}^{e}\right)(1-\operatorname{tax})} .
$$

\section{- Aggregate Supply}

Aggregate supply in this economy is described by the profit maximizing behavior of the firm and by the availability of labor, i. e. by the minimum of the notional supply of the firm at any real wage and the productive capacity of the economy $F\left(L_{\max }\right)=y_{\max }$ :

$$
y_{t}^{s}=\min \left\{F\left(h\left(\alpha_{t}\right)\right), F\left(L_{\max }\right)\right\} \text {. }
$$

Feasibility for the economy as a whole requires that actual output is determined by the minimum of aggregate demand and aggregate supply. Thus, for any period $t$, given government parameters $(g, \operatorname{tax})$, current prices and wages, expected prices, and money holdings of the old consumer, a state of the economy in period $t$ is uniquely defined by actual output $y_{t}$ given by

$$
y_{t}=\min \left\{y_{t}^{D}, y_{t}^{*}, y_{\max }\right\}=\mathcal{Y}\left(p_{t}, w_{t}, M_{t}, p_{t+1}^{e}, g, \operatorname{tax}\right)
$$


and by employment $L_{t}$ given by

$$
L_{t}=F^{-1}\left(\mathcal{Y}\left(p_{t}, w_{t}, M_{t}, p_{t+1}^{c}, g, \operatorname{tax}\right)\right)=\mathcal{L}\left(p_{t}, w_{t}, M_{t}, p_{t+1}^{e}, g, \operatorname{tax}\right)
$$

Here $\mathcal{Y}$ and $\mathcal{L}$ denote the associated functions. It is straightforward to verify the statements made in the following theorem.

Theorem: Given Assumptions C, F, then:

$$
\forall\left(p_{t}, w_{t}, p_{t+1}^{e}\right) \gg 0, \quad \forall\left(M_{t}, g\right)>0, \quad \forall 0 \leq \operatorname{tax} \leq 1:
$$

1. $\exists$ unique positive feasible output and employment levels given by the two functions $\mathcal{Y}$ and $\mathcal{L}$

2. the type of temporary feasible state is either

$$
\begin{aligned}
& \text { C }- \text { classical } \\
& \text { K }- \text { Keynesian } \\
& \text { I }- \text { repressed inflation } \\
& \text { or one of the } 4 \text { boundary cases }{ }^{2} \text {, }
\end{aligned}
$$

3. the functions $\mathcal{Y}$ and $\mathcal{L}$ are continuous and homogeneous of degree zero in $\left(p_{t}, w_{t}, M_{t}, p_{t+1}^{e}\right)$. Hence, using the homogeneity property, one may write

$$
y_{t}=\mathcal{Y}\left(\alpha_{t}, m_{t}, \theta_{t}^{\epsilon}, g, \operatorname{tax}\right)
$$

and

$$
L_{t}=\mathcal{L}\left(\alpha_{t}, m_{t}, \theta_{t}^{e}, g, \operatorname{tax}\right)
$$

The important implication of the theorem is that temporary feasible states are uniquely defined by real wages, real balances, expected inflation rates, and by government parameters. Thus, the dynamic development of the economy can be described in a unique way by sequences of these same variables.

\section{Steady States and Perfect Foresight}

Consider the economy in period $t \gg 1$, assuming that economic activity started at some initial point $t=1$. Then, given the values for $\left(p_{t}, w_{t}, M_{t}, p_{t+1}^{e}, g, \operatorname{tax}\right)$ of period $t$, the functions $\mathcal{L}$ and

\footnotetext{
${ }^{2}$ See for example Böhm $[4]$ for the definitions of the disequilibrium types.
} 
$\mathcal{Y}$ determine the current disequilibrium situation of period $t$. Assume that government activity is stationary, i. e. the tax rate as well as government demand is constant over time. Then, the dynamic development of the economy is described by a sequence $\left\{p_{t}, w_{t}, M_{t}, p_{t+1}^{e}\right\}$ of prices, wages, money balances, and expected prices for each $t \geq 1$.

Expected prices are determined by the expectation function $\Psi$. Money balances are determined by the savings behavior of the young generation in each period. The possibility of forced savings under demand rationing of young consumers makes it necessary to describe actual savings of the young as a function of actual output and employment. Demand rationing situations on the commodity market in any period $t$ may involve rationing of three different agents, namely the government, the old consumer, or the young consumer. For a determinate outcome, therefore, it is necessary to define a specific rationing rule for the commodity market. It will be assumed here that under demand rationing the government is served first, then the old consumer, and then the young consumer. This implies that actual consumption of the young consumer in period $t$ for given output $y_{t}$ is given by

$$
x_{t}=\max \left\{0, y_{t}-g-\frac{M_{t}}{p_{t}}\right\} .
$$

As a consequence, actual savings of the young, i. e. initial money balances at the beginning of the next period are

$$
M_{t+1}=(1-\operatorname{tax}) p_{t} y_{t}-p_{t} x_{t}=p_{t}\left[\min \left\{y_{t} \frac{M_{t}}{p_{t}}+g\right\}-\operatorname{tax} y_{t}\right]
$$

This equation corresponds to the usual government budget constraint and constitutes one of the difference equations of the model. If there is no demand rationing of the old consumer, i. e. if $M_{t} / p_{t} \leq y_{t}-g$, then the change in the money stock is equal to the government deficit. Otherwise young agents are demand rationed to zero and savings is equal to total net income. Thus possible amounts of money unspent by the old consumer are destroyed and not distributed to the young.

The government budget constraint, the expectations function, and the allocation function $\mathcal{Y}$ can now be used to define steady states with perfect foresight, in spite of the fact that a specific price and wage adjustment process has not been defined. In general, sequences of temporary feasible states would be given by sequences of prices, wages, money balances, and price expectations. Due to the homogeneity of the allocation function, a three dimensional state space suffices with the coordinates for real wages, real money balances, and expected inflation rates. 
Def: A sequence $\left\{\alpha_{t}, m_{t}, \theta_{t}^{e}\right\}_{t=1}^{\infty}$ of real wages, real money balances, and expected inflation rates is called a path with quantity rationing, or simply a path, if

1. $m_{t+1} \theta_{t}=\min \left\{y_{t}, m_{t}+g\right\}-\operatorname{tax} y_{t}$

2. $\theta_{t}^{e}=\Psi\left(\theta_{t-1}, \ldots, \theta_{t-\tau}\right)$,

3. $y_{t}=\mathcal{Y}\left(\alpha_{t}, m_{t}, \theta_{t}^{e}, g, \operatorname{tax}\right)$.

Steady states imply constant allocations, i. e. constant levels of employment, production and consumption. These are generated by constant sequences of real wages, of real balances, and of expected inflation rates.

Def.: A path $\left\{\alpha_{t}, m_{t}, \theta_{t}^{e}\right\}_{t=1}^{\infty}$ is called quasi-stationary if

$$
\forall t, t^{\prime}: \alpha_{t}=\alpha_{t^{\prime}}, m_{t}=m_{t^{\prime}}, \theta_{t}^{e}=\theta_{t^{\prime}}^{e}
$$

The associated steady state is also called quasi-stationary. It is called stationary if $\theta_{t}^{e}=1$. It is immediately apparent that agents' price expectations are fulfilled at any quasi-stationary state, i. e. expected and actual inflation coincide. Moreover, non zero inflation $(\theta \neq 1)$ implies, of course, that nominal money balances grow or shrink at the same rate as prices and wages. Thus, for such states the government deficit has to be non zero. Conversely, the only steady states with a balanced government budget are those with zero inflation, i. e. $\theta=1$.

One of the striking results derived in [4] is that, in a slightly more general model, the set of steady states is a piecewise differentiable manifold which possesses a double fold. With this information it was conjectured that not all trajectories can be monotonically converging. The same property of the set of steady states holds here as well for the model with a more aggregate consumption sector and a proportional income tax.

Theorem: Given Assumptions C, E, F, let $y_{\max }=F\left(L_{\max }\right)$ denote capacity output and $\alpha^{*}=$ $F^{\prime}\left(L_{\max }\right)$ the full employment real wage. Then

$\forall g>0$ and $\forall 0 \leq \operatorname{tax} \leq 1$ one has:

1. $\forall(\theta, \alpha) \gg 0$, $\exists m>0$ s.t. $(\alpha, m, \theta)$ is quasi-stationary;

2. $\forall(\theta, \alpha) \gg 0$ and $\theta>1$ or $g>[1-c(\theta)(1-\operatorname{tax})] y_{\max }$ $\exists$ unique $m>0$ s.t. $(\alpha, m, \theta)$ is quasi-stationary; 


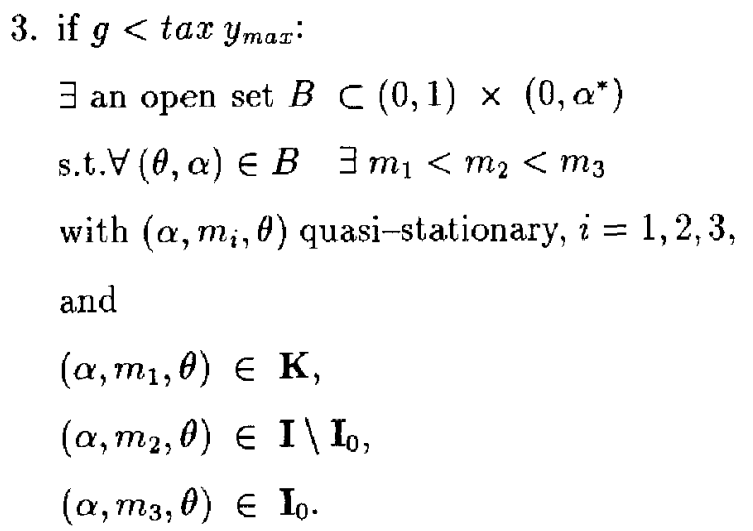

The set $\mathbf{I}_{0}$ denotes those states of repressed inflation where young consumers are rationed to zero. The multiplicity of steady states as given in property 3 of the theorem is again one primary source for the possibility of nonmonotonic, cyclical, or chaotic behavior. The numerical analysis of the last section indicates that the curvature of the double fold decreases with the degree of concavity of the production function. However, this is only one crucial parameter for the qualitative results obtained.

\section{Disequilibrium Price Adjustment - The Law of Supply and Demand}

For a complete description of the dynamic process the wage and price adjustment mechanisms have to be defined. In [4] a general class of market specific adjustment rules was proposed which transform disequilibrium signals on each market into an associated price or wage adjustment. The general principle is straightforward. Supply (demand) rationing in any particular period leaves a potential seller (buyer) unsatisfied, who then would be willing to sell for a lower (buy for a higher) price, leading to lower (higher) prices in the respective market in the next period. Such a rule corresponds most closely to an adjustment mechanism typically associated with a non-tâtonnement process. In this context it is immaterial whether this rule is implemented by an anonymous auctioneer, the government, or whether the producer and the worker follow it. Such a rule is essentially myopic. It is defined using exclusively information provided by the economy at date $t$ through the disequilibrium configuration on each market. Hence it does not take any past history of states or prices nor any expectations for the future into account.

Formally, the price and wage adjustment mechanism consists of two parts, namely the function determining the disequilibrium signals and the function determining the price and wage adjustment. Let $\left(s^{c}, s^{\ell}\right)$ denote a pair of numbers between minus one and plus one, describing disequilibrium measures or signals for the commodity and for the labor market respectively. They are best interpreted to 
indicate percentages of unsatisfied desired transactions, but other monotonic transformations could be used as well. Negative numbers mean supply rationing, positive numbers mean demand rationing. Thus, for example, $s^{\ell}=-0.3$ could indicate an unemployment rate of 30 per cent. These measures depend on the disequilibrium state in every period, i. e. on the three variables $\left(\alpha, m, \theta^{e}\right)$. Therefore, the two associated signaling functions $\sigma^{c}$ and $\sigma^{\ell}$ generating the measures are defined on the state space $\mathbb{R}^{3}$ of the economy.

$$
\begin{aligned}
& \sigma^{c}: \mathbb{R}_{++}^{3} \rightarrow[-1,+1] \quad ; \quad s^{c}=\sigma^{c}\left(\alpha, m, \theta^{e}\right) \\
& \sigma^{\ell}: \mathbb{R}_{++}^{3} \rightarrow[-1,+1] ; \quad s^{\ell}=\sigma^{\ell}\left(\alpha, m, \theta^{c}\right)
\end{aligned}
$$

The signaling functions are consistent with the disequilibrium state if the following assumption is satisfied.

Assumption P Part 1: (Disequilibrium Signaling)

$$
\begin{gathered}
\sigma^{c}\left(\alpha, m, \theta^{e}\right)= \begin{cases}>0 & \left(\alpha, m, \theta^{e}\right) \in \operatorname{int}(C \cup I) \\
<0 & \left(\alpha, m, \theta^{e}\right) \in \operatorname{int} K \\
=0 & \left(\alpha, m, \theta^{e}\right) \in K \cap C,\end{cases} \\
\sigma^{\ell}\left(\alpha, m, \theta^{e}\right)= \begin{cases}>0 & \left(\alpha, m, \theta^{e}\right) \in \operatorname{int} I \\
<0 & \left(\alpha, m, \theta^{e}\right) \in \operatorname{int}(C \cup K) \\
=0 & \left(\alpha, m, \theta^{e}\right) \in C \cap I,\end{cases} \\
\sigma^{\ell}\left(\alpha, m, \theta^{e}\right)>\sigma^{c}\left(\alpha, m, \theta^{e}\right)=0 \quad \text { if }\left(\alpha, m, \theta^{e}\right) \in(K \cap I) \backslash W E, \\
\sigma^{\ell}, \sigma^{c} \text { continuous except on } K \cap I .
\end{gathered}
$$

The first two sets of conditions present the natural notion of disequilibrium, i. e. indicating actual rationing if and only if the measure is nonzero. Continuity seems to be a normal requirement. However, in the present model, this cannot be guaranteed on the boundary $K \cap I \backslash W E$. This results exclusively from the structural asymmetry of the model with intertemporal consumption decisions and atemporal production decisions. This discontinuity would not arise in a model where both sectors have a true intertemporal decision problem.

The price and wage adjustment functions now map the disequilibrium signals of any period in a continuous and sign preserving fashion into rates of price or wage change as discussed above, a rule which may be called the Law of Supply and Demand. 
Assumption P Part 2: (The Law of Supply and Demand)

$$
\begin{gathered}
\mathcal{P}:[-1,1] \rightarrow(-1,+\infty) \quad p_{t+1}=p_{t}\left(1+\mathcal{P}\left(s_{t}^{c}\right)\right) \\
\mathcal{W}:[1,1] \rightarrow(-1,+\infty) \quad w_{t+1}=w_{t}\left(1+\mathcal{W}\left(s_{t}^{\ell}\right)\right) \\
\mathcal{P}(0)=0 \quad \mathcal{W}(0)=0 \\
\mathcal{P}, \mathcal{W} \text { continuous, monotonically increasing }
\end{gathered}
$$

A price and wage adjustment rule satisfying Assumption $\mathbf{P}$ Parts 1 and 2 will be called consistent. With these specifications the description of the dynamic system is now complete. There are essentially two equivalent functional forms which can be used to describe the dynamic process. One form considers the expected inflation rate $\theta_{t}^{e}$ as the third state variable whereas the other one considers the actual inflation rate $\theta_{t}$. In either case the difference equation is of order $\tau$ from $\mathbb{R}_{+}^{3}$ to itself. If $\tau=0$, or in some other special cases where expectations 'don't matter', the dynamic system reduces to a first order difference equation from $\mathbb{R}_{+}^{2}$ to itself. Here, the formulation with expected inflation rates is given.

Def.: A sequence $\left\{\alpha_{t}, m_{t}, \theta_{t}^{e}\right\}_{t=1}^{\infty}$ is called a consistent path, i. e. a disequilibrium path with consistent price adjustment, if

$$
\begin{aligned}
\alpha_{t+1} & =\alpha_{t} \frac{1+\mathcal{W}\left(s_{t}^{\ell}\right)}{1+\mathcal{P}\left(s_{t}^{c}\right)} \\
m_{t+1} & =\frac{1}{\theta_{t}}\left[\min \left\{y_{t}, m_{t}+g\right\}-\operatorname{tax} y_{t}\right] \\
\theta_{t+1}^{e} & =\Psi\left(\theta_{t}, \ldots, \theta_{t+1-\tau}\right),
\end{aligned}
$$

such that

$$
\begin{aligned}
& y_{t}=\mathcal{Y}\left(\alpha_{t}, m_{t}, \theta_{t}^{e}, g, \operatorname{tax}\right), \\
& s_{t}^{j}=\sigma^{j}\left(\alpha_{t}, m_{t}, \theta_{t}^{e}\right) \quad j=c_{,} \ell \\
& \theta_{t}=1+\mathcal{P}\left(s_{t}^{c}\right) .
\end{aligned}
$$

It is straightforward to verify the following properties of consistent steady states. If $(\alpha, m, \theta)$ is consistent and quasi-stationary, then

1. $\theta^{e}=\theta$,

2. $(\alpha, m, \theta) \notin C$, 
3. $\theta>1 \quad$ iff,$\quad(\alpha, m, \theta) \in I$,

$\theta=1 \quad$ iff $\quad(\alpha, m, \theta) \in W E$

$\theta<1 \quad$ iff $\quad(\alpha, m, \theta) \in K$.

Expectations are fulfilled in consistent steady states and states can never be of the classical unemployment type. Keynesian unemployment states must be deflationary, whereas states of repressed inflation must have a positive inflation rate. Moreover, as the following theorem indicates, the type of steady state strictly depends on the production characteristics of the economy and on the relative sizes of government demand to taxes, but neither on the adjustment speeds on any of the markets nor on consumer characteristics.

Theorem: If Assumptions $\mathbf{C}, \mathbf{E}, \mathbf{F}, \mathbf{P}$ hold, then there exists a unique steady state $(\alpha, m, \theta)$, such that

$$
\begin{array}{lll}
(\alpha, m, \theta) \in K & \text { iff } & g<\operatorname{tax} F\left(L_{\text {max }}\right) \\
(\alpha, m, \theta) \in W E & \text { iff } & g=\operatorname{tax} F\left(L_{\text {max }}\right) . \\
(\alpha, m, \theta) \in I & \text { iff } & g>\operatorname{tax} F\left(L_{\text {max }}\right)
\end{array}
$$

\section{Simulation Results}

In spite of the fact that the uniqueness of steady states and their qualitative properties are obtained quite easily, the dynamic properties of the system seem intractable on the general level of the model so far. Even for the simplest case with no expectations memory $(\tau=0)$, the resulting planar system of a first order difference equation has a sufficient amount of complexity, so that only numerical techniques are capable of generating global dynamic results. Therefore a class of parametric specifications of the assumptions $\mathbf{C , E}, \mathbf{F}, \mathbf{P}$ is chosen for which some of the simulation results are presented in this section.

Assumption C: For $\delta>0$ and $-\infty<\rho<1$ :

$$
u\left(x_{t}, x_{t+1}\right)= \begin{cases}\frac{1}{\rho}\left[x_{t}^{\rho}+\delta x_{t+1}^{\rho}\right] & \rho \neq 0 \\ \ln x_{t}+\delta \ln x_{t+1} & \rho=0\end{cases}
$$

$\mathbf{C}$ is the standard CES intertemporal utility function with substitution parameter $\rho$ and time discount parameter $\delta$. The Cobb-Douglas case, i. e. $\rho=0$, implies that current demand is independent 
of expected prices. In this situation the dynamics are independent of expectations. Thus the system is two-dimensional and of first order regardless of the length of memory $\tau$ and of the expectations function $\Psi$.

Assumption $\mathbf{E}$ : For $\tau=0,1,2,3, \ldots$ and $T=\min \{t-1, \tau\}$ :

$$
\theta_{i}^{e}=\frac{p_{t+1}^{e}}{p_{t}}= \begin{cases}\frac{1}{T} \sum_{k=1}^{T} \theta_{t-k} & T>0 \\ 1 & T=0 .\end{cases}
$$

This expectations function is a simple unweighted averaging procedure. No attempt has been made to match a sophisticated econometric forecasting method.

Assumption F: For $A>0$ and $1>B>0$ :

$$
y_{t}=\frac{A}{B} z_{t}^{B}
$$

Assumption P: For $0<\gamma<1,0<\kappa<1$ :

$$
P_{t+1}=P_{t} \begin{cases}1+\gamma \frac{y_{t}^{D}-y_{t}}{y_{t}^{D}} & y_{t}^{D}>y_{t} \\ 1+\kappa \frac{y_{t}-y_{t}^{*}}{y_{t}^{*}} & \text { otherwise }\end{cases}
$$

and for $0<\mu<1,0<\lambda<1$ :

$$
w_{t+1}=w_{t} \begin{cases}1+\lambda \frac{L_{t}-L_{\max }}{L_{\max }} & L_{\max }>L_{t} \\ 1+\mu \frac{z_{t}^{*}-L_{t}}{z_{t}^{*}} & \text { otherwise. }\end{cases}
$$

Here the disequilibrium measures are the usual effective excess demand percentages, and the adjustment functions $\mathcal{P}$ and $\mathcal{W}$ are linear with constant parametrically chosen adjustment coefficients.

Apart from the two government parameters $(g, \operatorname{tax})$, the assumptions $\mathbf{C}, \mathbf{E}, \mathbf{F}, \mathbf{P}$ require the numerical specification of ten parameter values: $\left(\delta, \rho, \tau, L_{\max }\right)$ for the consumer, $(A, B)$ for the producer, and the adjustment coefficients $(\gamma, \kappa, \lambda, \mu)$ for the two markets. $L_{m a x}$ and $A$ are essentially scaling parameters which can be set equal to one without loosing too much structural information. As a 
consequence the real wage $\alpha^{*}$ which clears the labour market is also equal to one for all other possible parameter values. This leaves eight parameters plus $(g, \operatorname{tax})$ to be chosen.

The available numerical results so far represent the characteristics of the model for a partial range of parameter variations only. However, they show four distinct structural features which are not attributed usually to standard macroeconomic models of the Keynesian kind and which imply the possibility of a wide range of endogenous business cycles. Judging these features from the point of view of modern dynamic theory, they supply a consistent picture of a highly complex nonlinear system which is capable of generating a multitude of different dynamic paths.

- First, there are large sets of parameter values for which the unique steady state is stable and others for which it is unstable. There seems to be no immediate heuristic or economically intuitive arguments which make stability or instability more plausible for certain sets than others.

- Second, there are large sets of values for some parameters such that there exist stable cycles of order $2,3,4,5,7,9$, and higher, as well as their multiples, depending on the values of the remaining parameters. For example, for a set of $(\delta, \rho, \tau, B, \gamma, \kappa, \lambda, \mu)$ different values of $(g, \operatorname{tax})$ generate the above mentioned cycles. Thus, an economist may conclude, that, other things being equal, different economic policies 'cause' business cycles of different degrees.

- Third, continuous changes of some parameters generate the typical bifurcation phenomenon of period doubling. This is to be expected knowing that there exist stable cycles of different order depending on the values of one parameter, other things being equal. Hence, for small changes of some parameters the stability of a cycle of order $k$ is lost and the system changes to a stable cycle of order $2 k$ or $k / 2$, as the case may be.

- Fourth, for open sets of parameter values, no stable cycles exist and long iterated sequences show all features of irregular, possibly chaotic, orbits. The associated trajectories form so called strange attractors which are independent of initial conditions.

The following set of parameter values can be considered as a benchmark which may serve as a reference point for the discussion:

$$
\rho=0, \delta=1, B=.5, \gamma=\kappa=\lambda=\mu=.5, g=1, \operatorname{tax}=.5
$$

There are no deep economic reasons for chosing these values. The Cobb-Douglas utility function with no time preference, i. e. $\rho=0$ and $\delta=1$, is an economic benchmark. The next six values are just the midpoints of their allowable intervals. Given these, $g=1$ yields a Walrasian steady state 
with half of total output consumed by the government. All numerical experiments with these values show convergence to the WE for any initial conditions $\left(p_{1}, w_{1}, M_{1}\right)$. The same is true for parameter values 'close by' with any memory between zero and twenty. No cycles of higher order were found. Thus, the steady state seems globally stable for all values near the benchmark case.

The experiments also revealed that all of the four features listed above can be obtained for systems with $\rho=0$, i. e. for the simplest two dimensional system where expectations and memory do not matter. On the other hand no specific features have been detected in experiments with values for $\rho \neq 0$ and $\tau>0$ which were not reproducible for a model with $\rho=0$. Therefore, all further results reported here deal with the case of $\rho=0$ only. It is still an open question left for further experimentation to what extent expectations and memory matter, especially given the sensitivity of many standard macroeconomic models to those two elements.

Among the many situations for which the unique steady state is unstable the results of three experiments are reported here. These were designed to answer the following questions:

1. Do high price and wage adjustment coefficients lead to instability whereas low coefficients do not?

2. To what extent are the features of the technology, i. e. the concavity of the production function, responsible for instability, cycles, and possibly chaos?

3. What role do the government parameters play for instability, cycles, and possibly chaos?

No decisive answer seems possible from the experiments so far with respect to the values of the adjustment coefficients. Cycles appeared for values higher than 0.6 , but also for values lower than 0.2. In other cases stability could be exhibited for these values. More experiments are necessary to determine whether adjustment coefficients alone can control stability or instability.

The production parameter $B$ is a measure for the concavity of the production function which decreases with increasing values for $B$. Preliminary experiments show that for $B<0.6$ instability of the steady state does not occur. However, for values between 0.75 and 0.95 many stable cycles of higher order exist. A full range analysis of the role of the production parameter still has to be carried out. The preliminary results seem to suggest that low values for $B$, i. e. strong curvature, eliminate cycles. But it is unclear whether these results are decisive.

The following four diagrams show some of the typical situations where the steady state is unstable. They depict the set of parameters, the time paths for the employment level and for the two state variables $\left(\alpha_{t}, m_{t}\right)$, plus the attractor in state space. 


\begin{tabular}{|c|c|c|c|}
\hline \multicolumn{4}{|c|}{ Model my3cycle } \\
\hline $\begin{array}{ll}\text { A: } & 1.000 \\
\text { B: } & 0.900 \\
\text { Lmax: } & 1.000 \\
\text { g: } & 0.270 \\
\text { tax: } & 0.270\end{array}$ & $\begin{array}{lr}\text { gamma: } & 0.600 \\
\text { kappa: } & 0.600 \\
\text { lambda: } & 0.600 \\
\text { my: } & 0.600 \\
\text { tau: } & 10.000\end{array}$ & $\begin{array}{l}\text { delta: } \\
\text { rho: } \\
\text { wo: } \\
\text { po: } \\
\text { mo: }\end{array}$ & $\begin{array}{r}1.000 \\
0.000 \\
3.000 \\
5.000 \\
20.000\end{array}$ \\
\hline
\end{tabular}
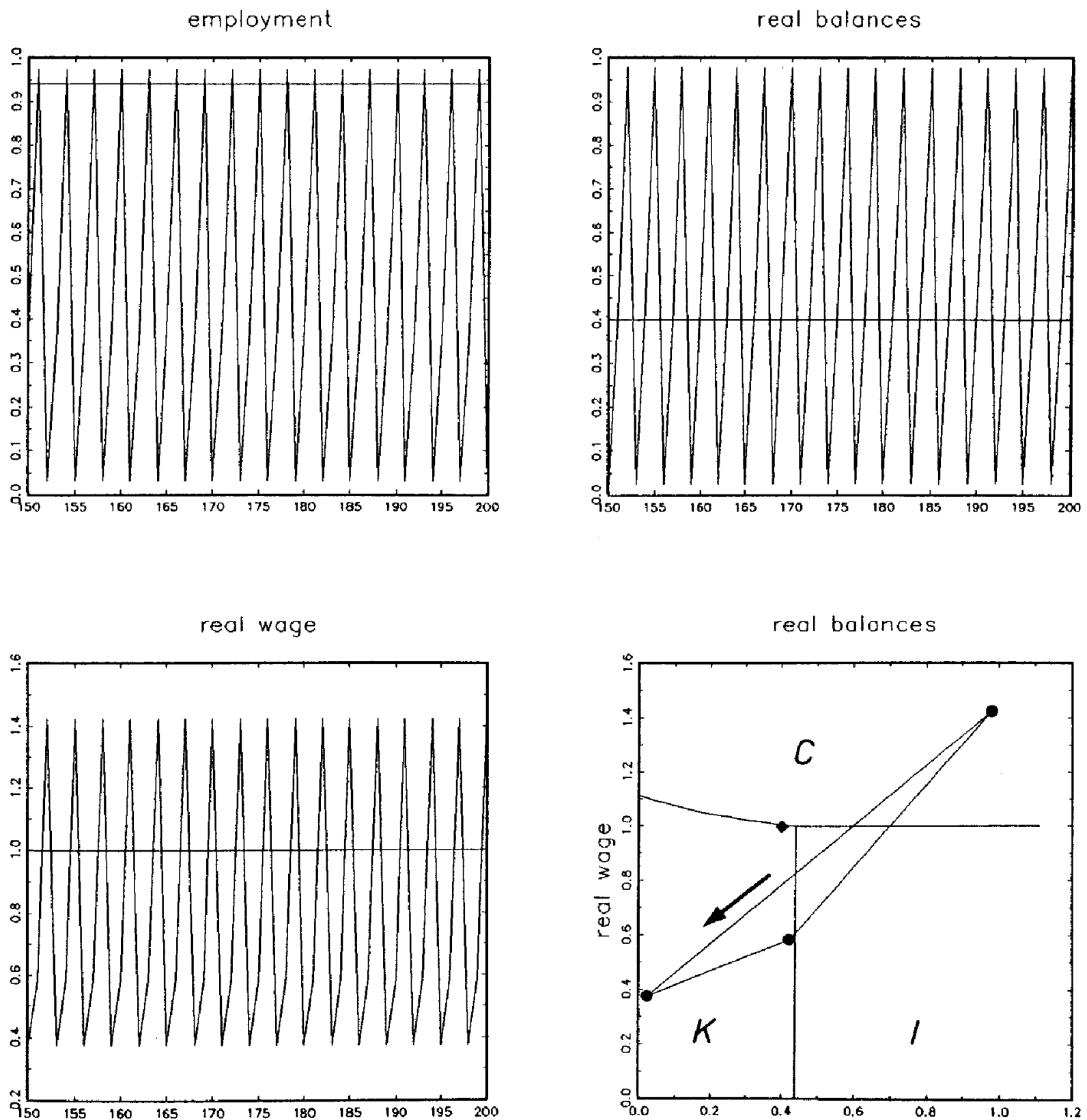

Figure 1: A three cycle 


\begin{tabular}{|c|c|c|c|}
\hline \multicolumn{4}{|c|}{ Model my5cycle } \\
\hline $\begin{array}{lr}\text { A: } & 1.000 \\
\text { B: } & 0.900 \\
\text { Lmax: } & 1.000 \\
\text { g: } & 0.040 \\
\text { tax: } & 0.270\end{array}$ & $\begin{array}{lr}\text { gamma: } & 0.600 \\
\text { kappa: } & 0.600 \\
\text { lambda: } & 0.600 \\
\text { my: } & 0.600 \\
\text { tau: } & 10.000\end{array}$ & $\begin{array}{l}\text { delto: } \\
\text { rho: } \\
\text { wo: } \\
\text { po: } \\
\text { mo: }\end{array}$ & $\begin{array}{r}1.000 \\
0.000 \\
3.000 \\
5.000 \\
20.000\end{array}$ \\
\hline
\end{tabular}

employment

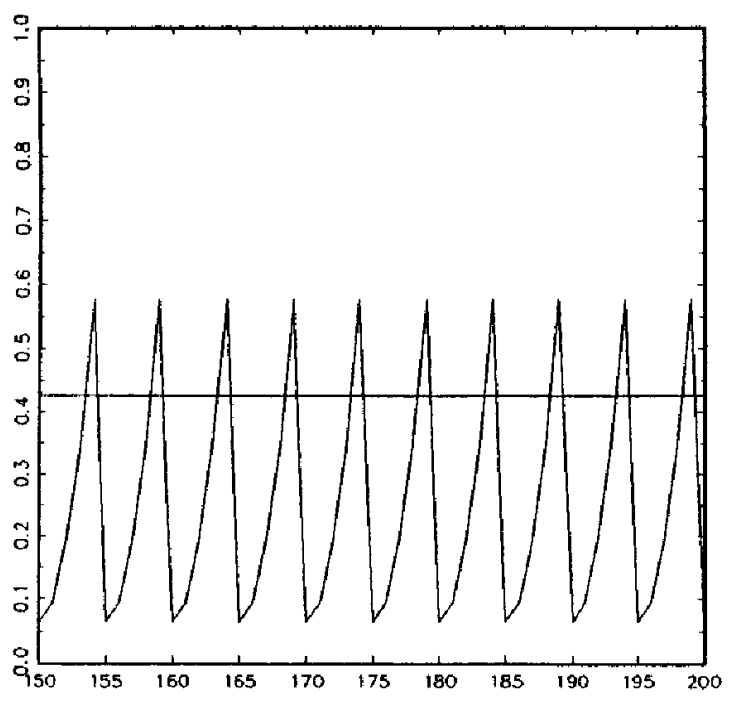

real wage

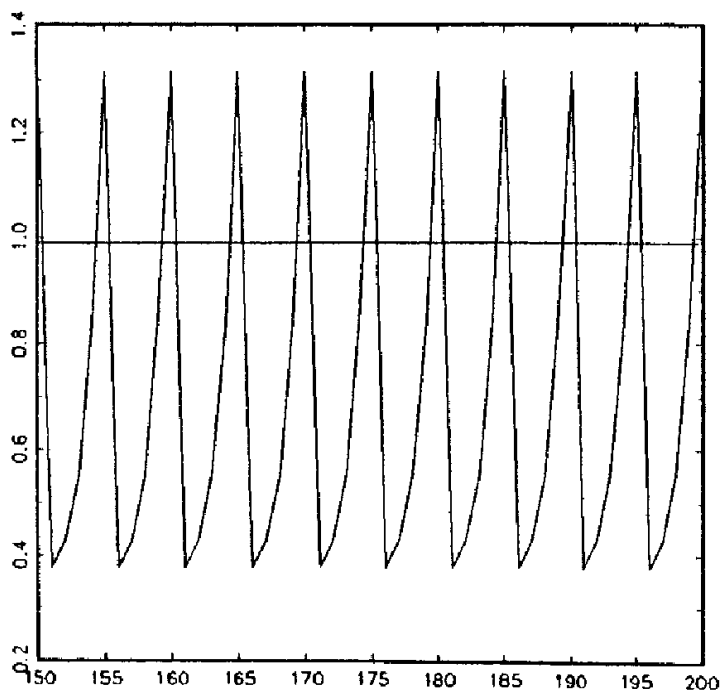

real balances

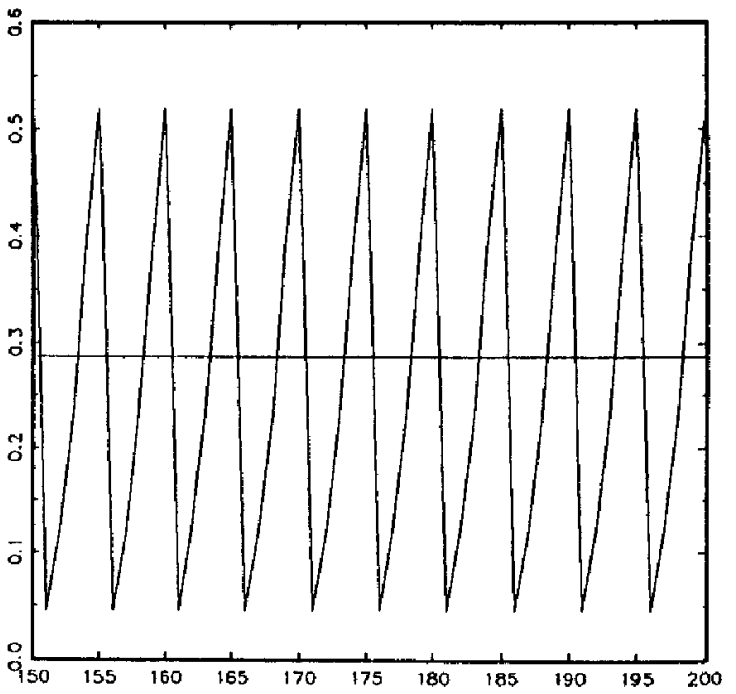

real bolances

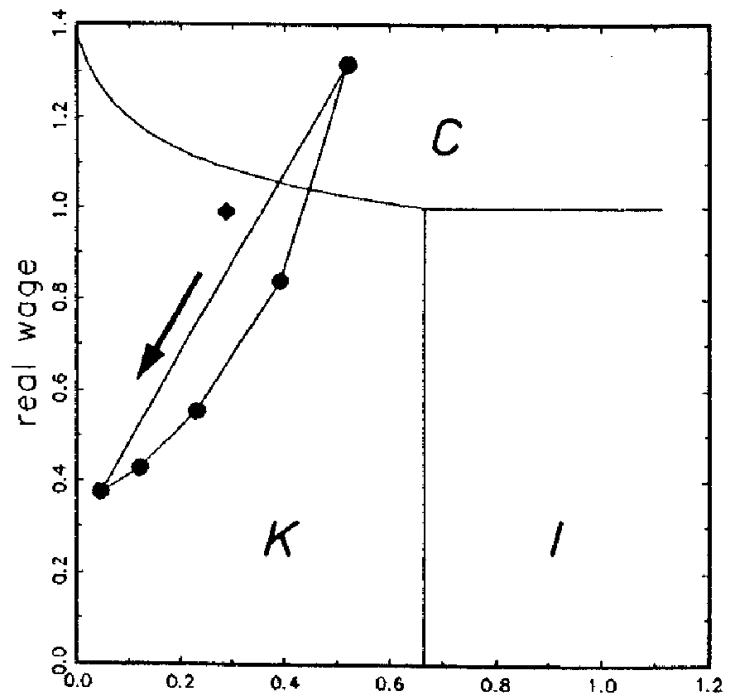

Figure 2: A five cycle 


\begin{tabular}{|c|c|c|c|}
\hline \multicolumn{4}{|c|}{ Model my9cycle } \\
\hline $\begin{array}{lr}\text { A: } & 1.000 \\
\text { B: } & 0.900 \\
\text { Lmax: } & 1.000 \\
\text { g: } & 0.323 \\
\text { tax: } & 0.270\end{array}$ & $\begin{array}{lr}\text { gamma: } & 0.600 \\
\text { kappa: } & 0.600 \\
\text { lambda: } & 0.600 \\
\text { my: } & 0.600 \\
\text { tau: } & 10.000\end{array}$ & $\begin{array}{l}\text { delta: } \\
\text { rho: } \\
\text { wo: } \\
\text { po: } \\
\text { mo: }\end{array}$ & $\begin{array}{r}1.000 \\
0.000 \\
3.000 \\
5.000 \\
20.000\end{array}$ \\
\hline
\end{tabular}
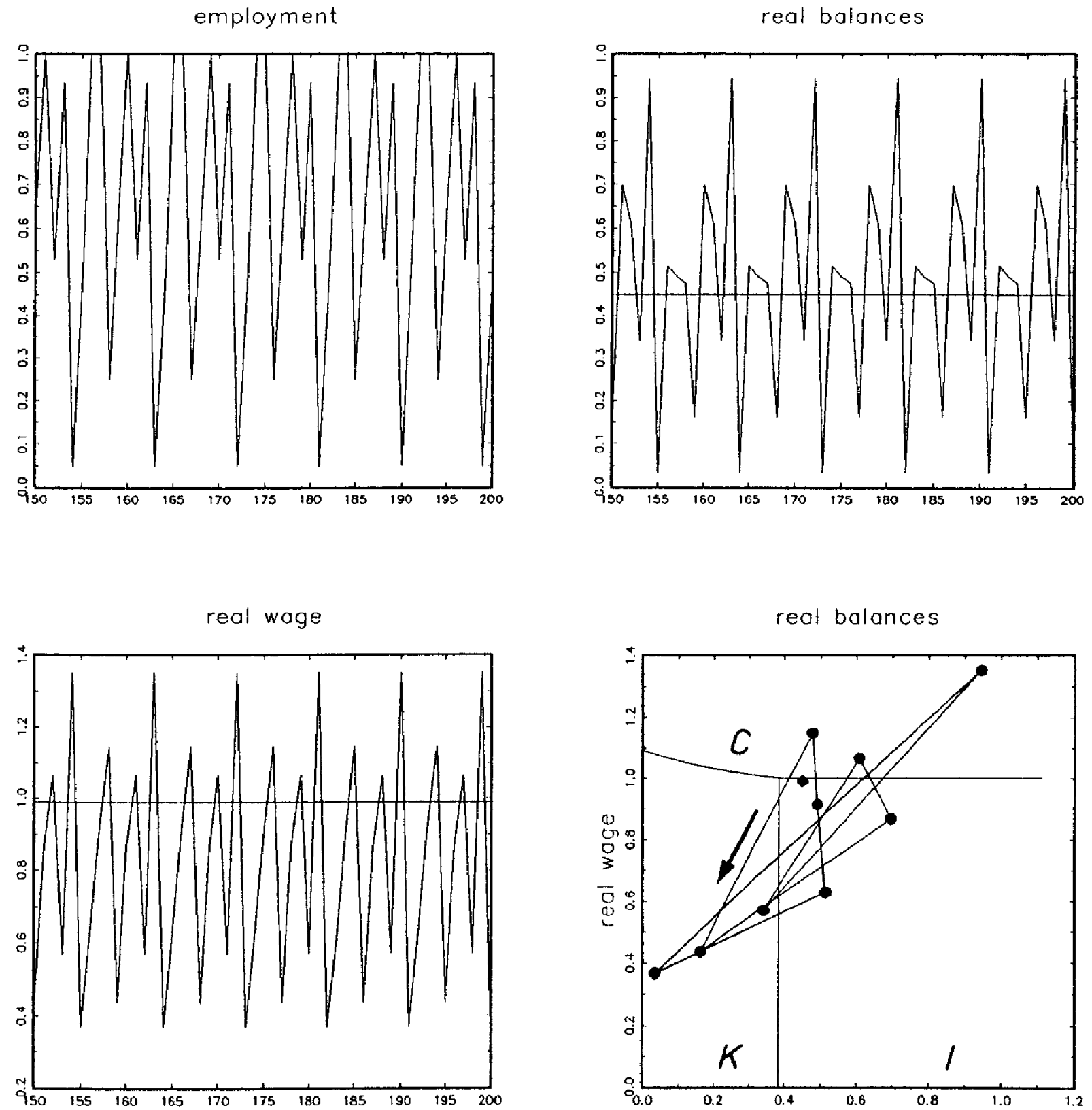

Figure 3: A nine cycle 


\begin{tabular}{|c|c|c|c|}
\hline \multicolumn{4}{|c|}{ Model mychoosa } \\
\hline $\begin{array}{ll}\text { A: } & 1.000 \\
\text { B: } & 0.900 \\
\text { Lmax: } & 1.000 \\
\text { g: } & 0.300 \\
\text { tax: } & 0.270\end{array}$ & $\begin{array}{lr}\text { gamma: } & 0.600 \\
\text { kappa: } & 0.600 \\
\text { lambda: } & 0.600 \\
\text { my: } & 0.600 \\
\text { tau: } & 10.000\end{array}$ & $\begin{array}{l}\text { delta: } \\
\text { rho: } \\
\text { wo: } \\
\text { po: } \\
\text { mo: }\end{array}$ & $\begin{array}{r}1.000 \\
0.000 \\
3.000 \\
5.000 \\
20.000\end{array}$ \\
\hline
\end{tabular}

employment

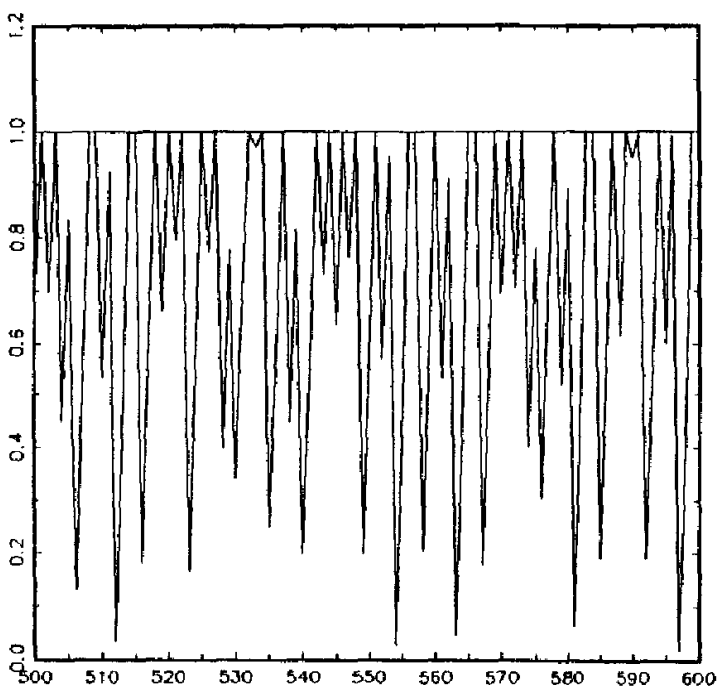

real wage

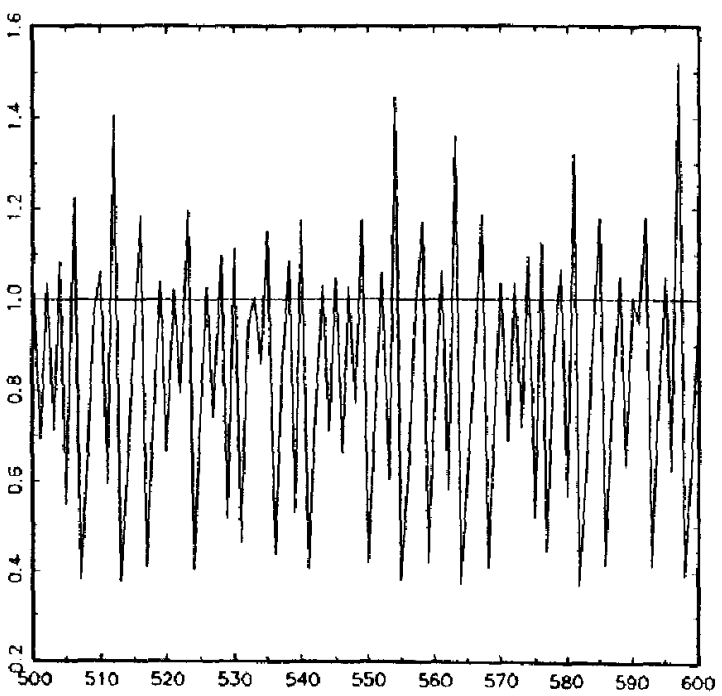

real balances

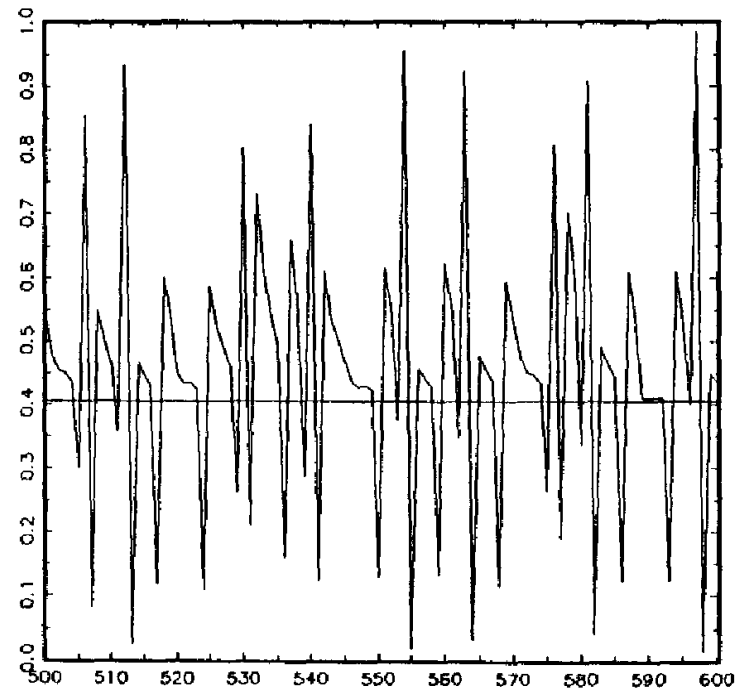

real bolances

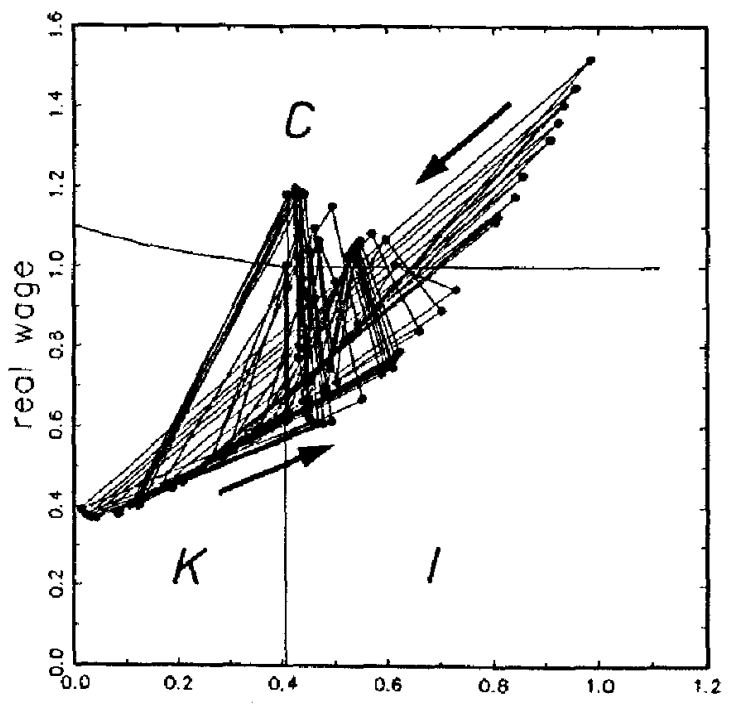

Figure 4: Irregular behavior 
The square dot marks the location of the steady state and the arrows indicate the orientation of the cycles. The first three figures show cycles of order 3,5 , and 9 . Since they are converging relatively fast, iterations of less than 100 periods were sufficient to obtain exact cycles. The time series plotted show the values for periods 150 to 200 .

All three cycles exhibit a counterclockwise orientation. The pattern of regime switching is quite different between them, as is the location of the steady state. Notice, however, that the parameter sets differ only in the level of government demand and not in the adjustment coefficients $(\gamma, \kappa, \lambda, \mu)$, as one might have expected. The parameters for the fourth model presented in the next diagram differ again only in the value of government demand. They are such that the steady state is a Walrasian equilibrium. The values for periods 500 to 600 are shown. The time series show quite strikingly that the behavior is non-cyclical, and the lines connecting the points in state space (the lower right hand box) reveal the complexity of the orbit. Figure 5 shows the values for periods 50,000 to 500,000 (!!) without the connecting lines which provides an indication of the shape of the attractor.

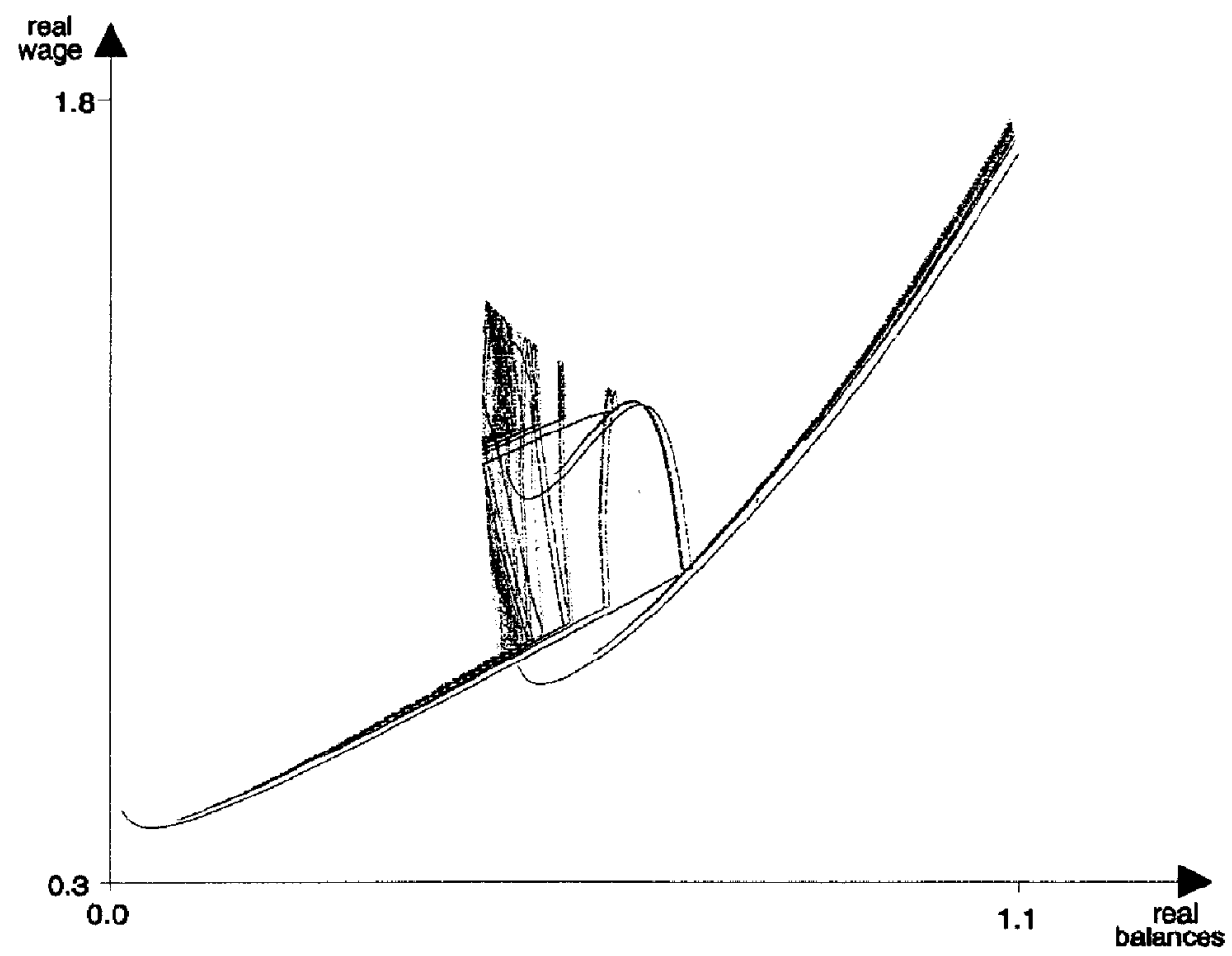

Figure 5 
Figures 6,7 and 8 display bifurcation graphs for changes of government demand keeping all other parameters as before. Since the state space is $\mathbb{R}_{+}^{2}$, a bifurcation graph is a subset of $\mathbb{R}_{+}^{3}$. Any graphical representation of such an object is some projection into the plane which, in general, cannot reveal the full dimensionality of the true graph, as can be seen from Figure 6 . Therefore, the real wage variable is plotted separately in Figure 7 and 8 . The first graph shows the whole range of $g$ between zero and one, while the second one shows an enlarged window for $0.25 \leq g \leq 0.55$. For each parameter value of $g$ an iteration of 2,000 periods has been carried out and the values for the last 700 periods are plotted.

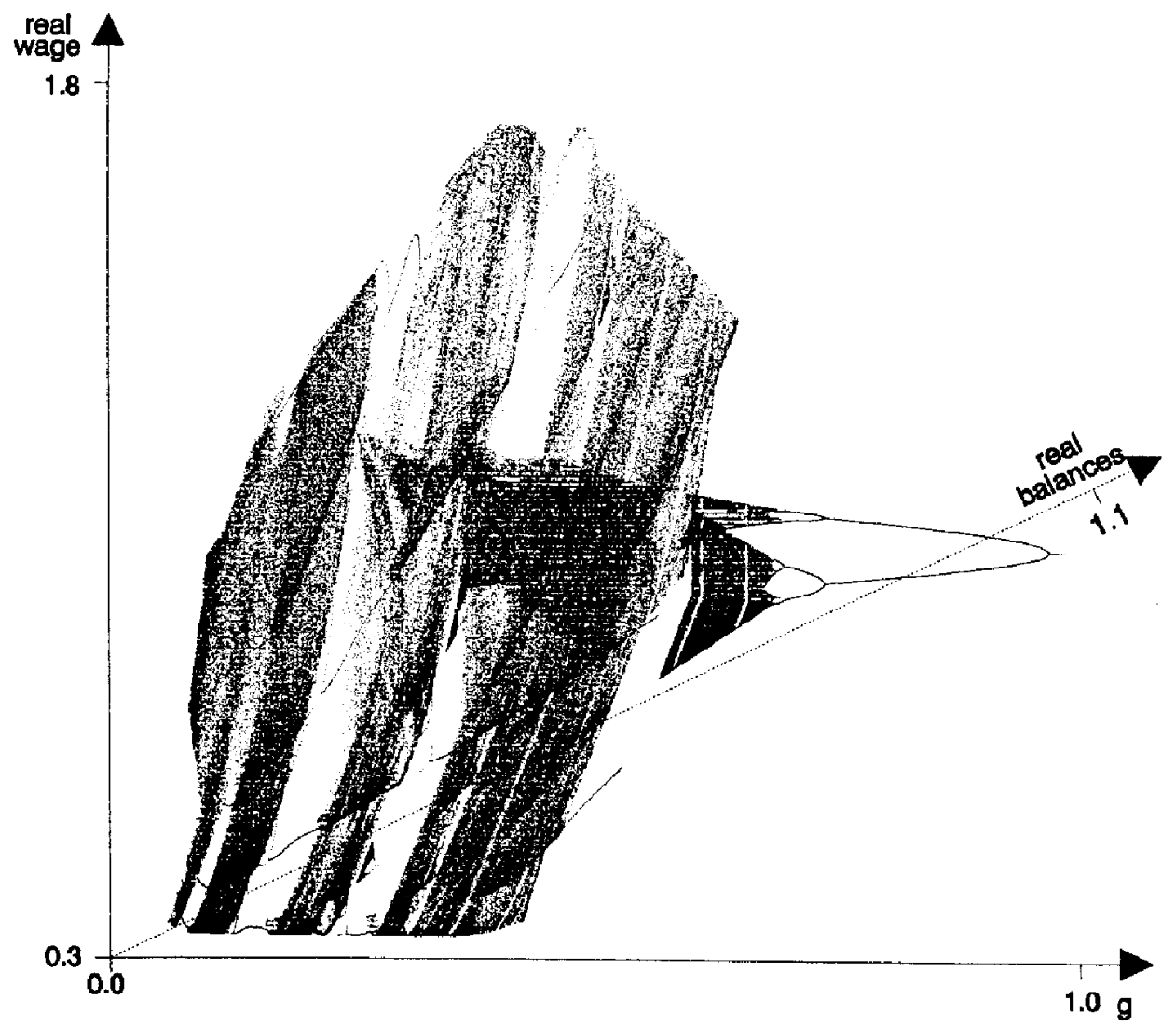

Figure 6: A 3D bifurcation 
The last two diagrams show the typical bifurcation phenomenon known from the one-dimensional logistic map, like period doubling, but also the window structure for ranges of cycles of different integer order between the ones with irregular orbits. Since the parameter sets between the first four diagrams and the bifurcation map coincide, it is easy to identify the location of the values of government demand which show the corresponding cycles as well as the value for the irregular attractor. The enlargement provides a finer view of the windows with cycles, including the one of order nine.

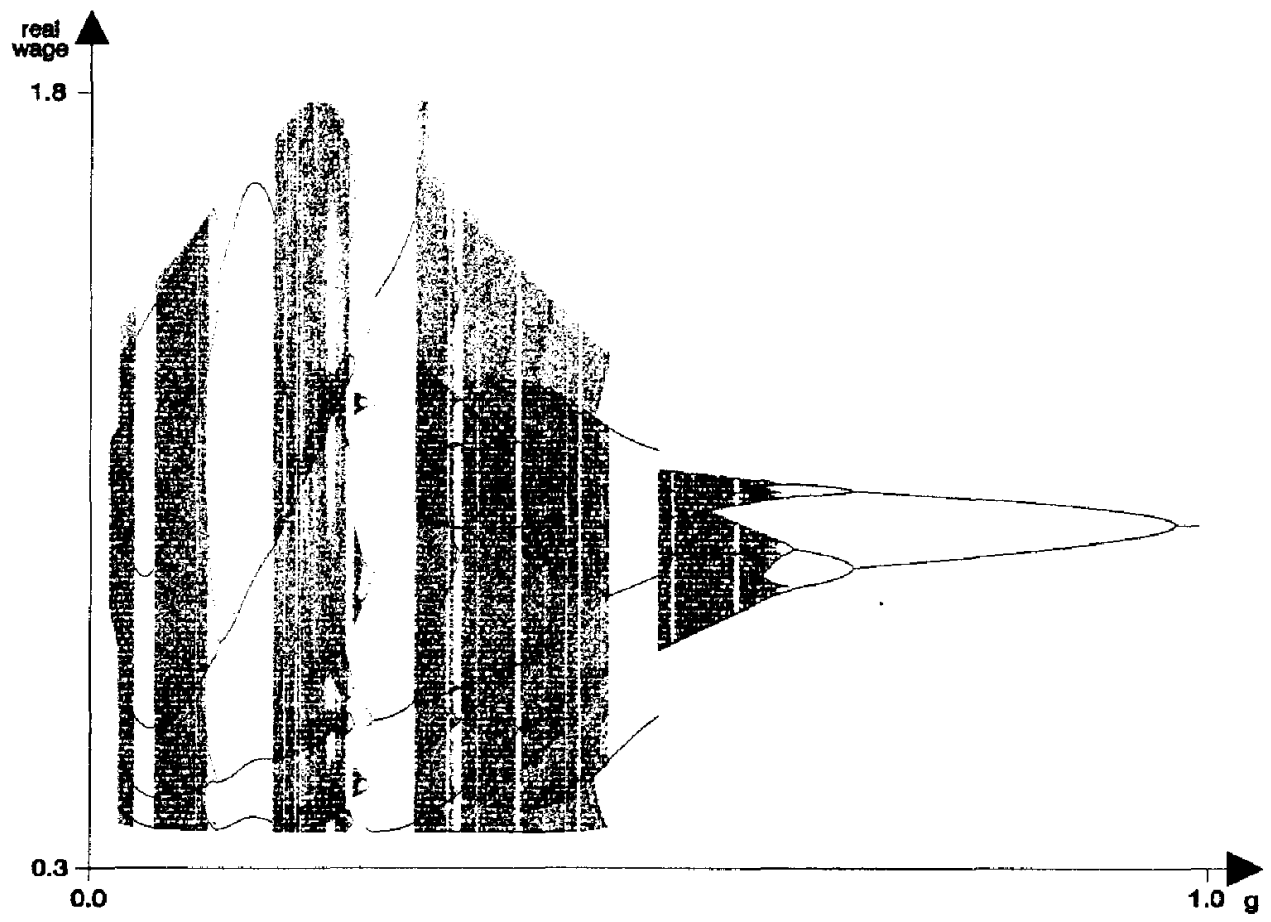

Figure 7 


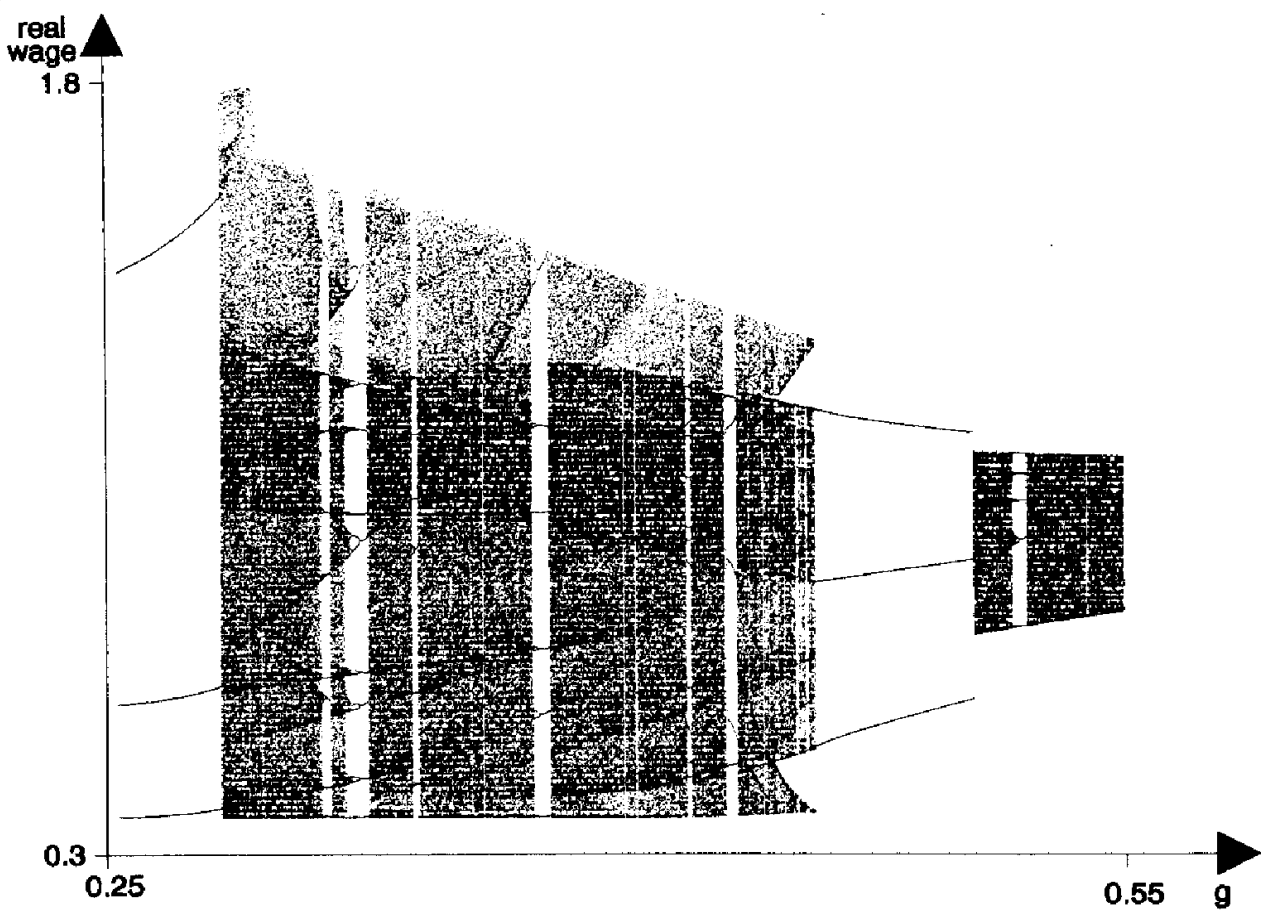

Figure 8

\section{$7 \quad$ Summary and Conclusions}

The model analysed in this paper represents a simple prototype of a consistent dynamic and full general equilibrium version of the standard Keynesian macroeconomic model. Its structure is completely stationary and its dynamic evolution is generated from fundamental principles of national income accounting, of feasibility, and of basic elements of temporary equilibrium analysis. In spite of its simplicity (no exogenous uncertainty, no inventories, no capital, etc.), the basic structure implies a highly complex nonlinear dynamic model which generates cycles of high order as well as irregular behavior endogenously. This shows that the Keynesian model, whether in this simple or in more extensive versions does supply a theoretical framework for studies of the business cycle.

This paper supplies only a first view of the dynamic features of the standard Keynesian model. It suggests that government demand for goods is a crucial bifurcation parameter. Further experiments should be designed to determine whether there are others and what their relationship is. One issue related to the question of the role of government is whether the model behaves in the same way if 
there is no government activity at all. From an economic point of view it also remains an intriguing question whether and why expectations in this model seem to play such a secondary role, a fact which contrasts sharply with current macroeconomic folklore. This question should be examined in a larger setting than here, including in particular different expectations functions. 


\section{References}

[1] Blanchard, O. J. and Fischer, S. 1989: Lectures on Macroeconomics. MIT Press.

[2] Blinder, A. S. and Solow, R. M. 1973: 'Does fiscal policy matter'. Journal of Public Economics, $2,319-37$.

[3] Böhm, V. 1978: 'Disequilibrium dynamics in a simple macroeconomic model'. Journal of Economic Theory, 17, 179-99.

[4] Böhm, V. 1989: Disequilibrium and Macroeconomics. Oxford: Basil Blackwell.

[5] Dana, R. A. and Malgrange, P. 1984: 'The Dynamics of a Discrete Version of a Growth Cycle Model'. in: J. P. Ancot (ed. ), Analysing the Structure of Economic Models, The Hague: Martinus Nijhoff, 205-222.

[6] Day, R. H. 1984: 'Disequilibrium Economic Dynamics'. Journal of Economic Behaviour and Organisation, 5, 57-76.

[7] Day, R. H. and Shafer, W. 1986: 'Keynesian Chaos'. Journal of Macroeconomics, 7, 277-295.

[8] Grandmont, J.-M. 1985: 'On Endogenous Competitive Business Cycles'. Econometrica, 53, 9951045.

[9] Grandmont, J.-M. 1988: 'Introduction'. In: J.-M. Grandmont (ed.), Temporary Equilibrium Selected Readings, Academic Press, London, xiii-xxiv.

[10] Grandmont, J.-M. and Malgrange, P. 1986: 'Nonlinear Economic Dynamics: Introduction'. Journal of Economic Theory, 40, 3-12.

[11] Hahn, F. 1982: Money and Inflation. Oxford: Basil Blackwell.

[12] Hénin, P. Y. and Michel, P. 1982: Croissance et accumulation en déséquilibre. Paris: Economica.

[13] Kaldor, N. 1940: 'A Model of the Trade Cycle'. Economic Journal, 50, 78-92.

[14] Lorenz, H.-W. 1993: 'Complexity in Deterministic, Nonlinear Business-Cycle Models - Foundations, Empirical Evidence, and Predictability'. this volume.

[15] Picard, P. 1983: 'Infiation and growth in a disequilibrium macroeconomic model'. Journal of Economic Theory, 30, 266-95.

[16] Tobin, J. and Buiter, W. 1976: 'Longrun effects of fiscal and monetary policy on aggregate demand'. In: J. Stein (ed.), Monetarism, Amsterdam: North Holland, 273-309. 